Document downloaded from:

http://hdl.handle.net/10251/109809

This paper must be cited as:

Pérez Zuriaga, AM.; García García, A.; Camacho-Torregrosa, FJ.; D'attoma, P. (2010). Modeling Operating Speed and Deceleration on Two-Lane Rural Roads with Global Positioning System Data. Transportation Research Record. 2171:11-20. doi:10.3141/217102

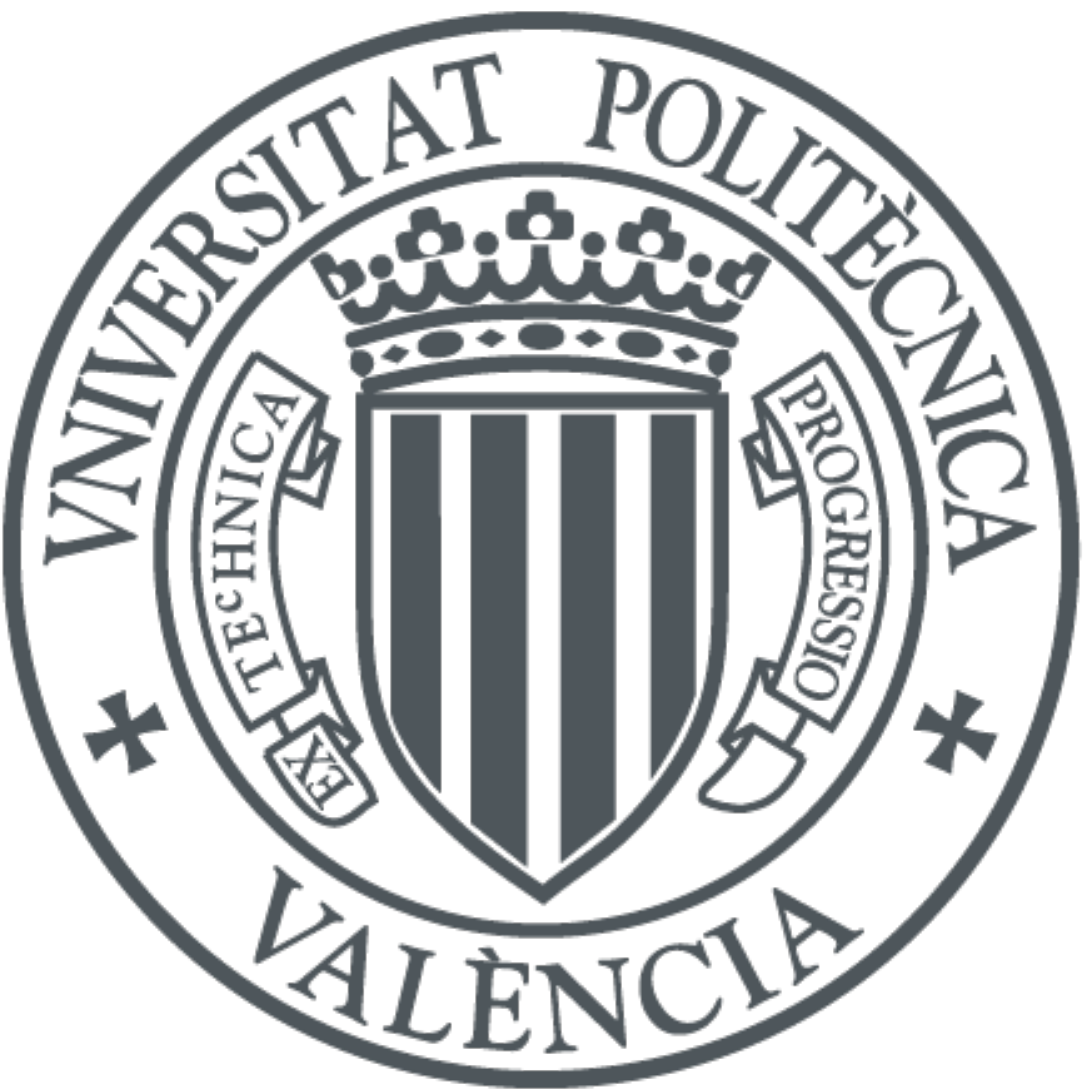

The final publication is available at

http://doi.org/ 10.3141/2171-02

Copyright Transportation Research Board

Additional Information 


\title{
MODELING OPERATING SPEED AND DECELERATION ON TWO-LANE RURAL ROADS WITH GLOBAL POSITIONING SYSTEM DATA
}

\author{
Ana Ma Pérez Zuriaga \\ $\mathrm{PhD}$ Candidate \\ Department of Transportation \\ Polytechnic University of Valencia \\ Camino de Vera, s/n. 46022 - Valencia \\ Tel: (34) 963877374 \\ Fax: (34) 963877379 \\ E-mail: anpezu@tra.upv.es

\section{Alfredo García García} \\ Professor \\ Department of Transportation \\ Polytechnic University of Valencia \\ Camino de Vera, s/n. 46022 - Valencia \\ Tel: (34) 963877374 \\ Fax: (34) 963877379 \\ E-mail: agarciag@tra.upv.es

\section{Francisco Javier Camacho Torregrosa} \\ $\mathrm{PhD}$ Candidate \\ Department of Transportation \\ Polytechnic University of Valencia \\ Camino de Vera, s/n. 46022 - Valencia \\ Tel: (34) 963877374 \\ Fax: (34) 963877379 \\ E-mail: fracator@posgrado.upv.es

\section{Pierangelo D'Attoma} \\ Civil Engineering Student \\ Department of Transportation \\ Polytechnic University of Valencia \\ Camino de Vera, s/n. 46022 - Valencia \\ Tel: (34) 963877374 \\ Fax: (34) 963877379 \\ E-mail: dattomap@libero.it
}




\begin{abstract}
In the road design process the speed variation along the road segment is an important issue to consider in order to adapt the road geometry to drivers' expectancies. To achieve this objective, speed criteria are used to evaluate road consistency. Therefore, being able to estimate the operating speed in the design phase can lead to a safer road alignment.

With this objective, several research have developed operating speed models. Most of these models are based on collected speed spot-data. They assume constant speed on curves and therefore deceleration occurs entirely on the approach tangent. According to these assumptions, speed spot-data are collected at the center of the horizontal curve and at the midpoint of the preceding tangent in order to obtain operating speed models.

This paper presents a new methodology based on the use of GPS devices that allow collecting and processing speed continuous data. By means of this new methodology, not only new and more accurate operating speed models can be developed, but also cited hypotheses can be checked. Observed speed continuous profiles allow new studies than previously couldn't be done, specially relating to deceleration and speed variations.

New speed models have been calibrated in this research, including three for horizontal curves with radius curve and CCR of a single curve as a variable explanatory, and one for tangents that incorporates the curve speed model. Moreover, tangent-curve speed variations have been evaluated, comparing $\Delta_{85} \mathrm{~V}$ and $\Delta \mathrm{V}_{85}$, analyzing the deceleration length occurring on curve, and developing two deceleration models.
\end{abstract}

KEYWORDS: operating speed, GPS, speed model, deceleration rate, speed profile. 


\section{INTRODUCTION}

Road safety is dependent of several factors; being the design consistency one of the most important, because it refers to the conformance of highway's geometry to driver expectancy. The design consistency verification is aimed to avoiding road alignment configurations which might surprise drivers and lead to anomalous behavior and possible collisions. A technique to evaluate the consistency of a design is to evaluate changes in operating speeds as a function of the roadway geometry. The operating speed $V_{85}$ is defined as the $85^{\text {th }}$ percentile of the distribution of speeds selected by drivers in free-flow conditions on a location of the road alignment. The estimation of $\mathrm{V}_{85}$ on the geometric elements of the alignment make possible to associate every location of the alignment to a value of $\mathrm{V}_{85}$ and to verify the design consistency.

Several models have been developed to predict the operating speed at curved sections. However, the model format, independent variables, and regression coefficients are substantially different from one model to the other. This might have been the result of differences in driver behavior from one region to others, and it highlights the fact that no single model is universally accepted.

In addition, the data collection device used to record vehicle speed was, in most cases, a manually operated radar gun or similar. The utilization of radar guns has three important problems: human error, cosine error and effect on driver behavior. Other methods to collect speed data are pavement sensors. However, they require the researcher to carry more equipment and require more time to install and remove the equipment. This method might also affect drivers' behavior.

By using these methods the speed data can only be collected in one location, usually the middle of the curve. Thus, operating speed models based in this data collection method have to assume a constant operating speed on curve, such as the model developed by Lamm (1). It estimates the operating speed on the curve from linear regression equations, using only the curvature change rate (CCR) of a single circular curve as the explanatory variable. The operating speed on tangent was assumed to be constant and estimated from the predicting model for speeds in curves, assuming CCR equal to zero. The acceleration and deceleration were assumed to occur only on tangent sections without validation, and their rates to be equal in magnitude $\left(0.85 \mathrm{~m} / \mathrm{s}^{2}\right)$.

Another model was developed by Ottesen and Krammes (2) based essentially on the same assumptions as Lamm. Spot-speed data were collected with radar guns at a sample of horizontal curves and their approach tangents on two-lane rural highways. The speeds of free-flowing passenger cars were measured only at the midpoint of the selected curves and on long tangent sections where desired speeds were believed to be attained.

Fitzpatrick and Collins (3) also developed a model based on spot-speed data, recorded at the center of the horizontal curve and at the midpoint of the preceding tangent (4). A family of speed models was developed with the curve radius or the rate of vertical curvature as explanatory variables for selected combinations of horizontal and vertical alignment conditions. However, a model for tangent speeds was not developed, using a value of $100 \mathrm{~km} / \mathrm{h}$ as an estimate of the speed on long tangents.

They also developed two models, to predict deceleration and acceleration rates as a function of radius. The models developed provide a maximum deceleration rate of $1 \mathrm{~m} / \mathrm{s}^{2}$ and a maximum acceleration rate of $0.54 \mathrm{~m} / \mathrm{s}^{2}$.

Estimation of speeds on curves may be easier than prediction of speeds on tangent sections. Few studies have dealt with this issue because a considerable database is necessary to identify any significant trends and substantial modeling effort is required. Polus et al. (5) analyzed the variability of the operating speeds on 162 tangent sections of two-lane rural highways where speed data were collected by using radar meters and on-pavement piezoelectric sensors connected to traffic counter-classifiers. Speeds were measured on the curve and on the preceding tangent. Several models were developed for prediction of operating speed based on the geometric characteristics available.

Concerning deceleration and acceleration rates, Collins and Krammes (6) tested the validity of speed-profile model for design consistency evaluation, including the speed reduction estimation ability of the model and the assumptions about deceleration and acceleration characteristics approaching and 
departing horizontal curves. It was found that the assumed $0.85 \mathrm{~m} / \mathrm{s}^{2}$ value is reasonable for deceleration rates approaching curves that require speed reductions but may overestimate acceleration rates departing curves. The model's assumptions that deceleration occurs entirely on the approach tangent and that speeds are constant throughout a curve were not confirmed by observed speed behavior.

On the other hand, there are models based on data collected at different sites along the curve and the preceding tangent.

Gibreel et al. (7) developed operating speed models for two-lane rural highways that account for the 3D nature of highways. Regression analysis was used to develop the operating speed models based on data collected for each highway section at five points along each travel direction to establish the effect of the $3 \mathrm{D}$ alignment combination on the trend of operating speed of the traveling vehicles.

Another study based on speed data collected at five different points on each curve was carried out by Misaghi and Hassan (8). In this case, the speed data were collected using electronic counter/classifiers to observe the vehicle speed change along 20 curves. They developed two models to estimate $85^{\text {th }}$ percentile speed at middle of curve with the radius as the explanatory variable and recommended 103.0 $\mathrm{km} / \mathrm{h}$ for independent tangents and $95.8 \mathrm{~km} / \mathrm{h}$ for nonindependent ones. Although relatively weak relationships were developed for the operating speed on horizontal curves, stronger relationships were found for the $85^{\text {th }}$ percentile speed differential from a tangent to a curve.

Figueroa and Tarko (9) evaluated driver behavior before and after horizontal curves in order to develop speed models for transition sections. Speeds were measured in each site at several spots distributed along estimated deceleration and acceleration segment. The results indicated that $66 \%$ of the speed reduction and $72 \%$ of the speed increase occurs on the tangents preceding and following the curves, respectively. In addition, the mean deceleration rate and the mean acceleration rate are 0.732 and $0.488 \mathrm{~m} / \mathrm{s}^{2}$, respectively, for a $16.1 \mathrm{~km} / \mathrm{h}$ reduction.

There are also models that predict the expected $85^{\text {th }}$ percentile of the deceleration and acceleration rates based on data collected on the tangent-curve-tangent transition in a driving simulator, such as Bella (10). In this study, the author found out that the mean value of the differences of speed of each driver between the beginning and the midpoint of the curve was not significantly different from zero, while that between the midpoint and the end was significantly different from zero. However, considering the low values of the differences of speed between the midpoint and the end of the curve, the simplified assumption of the constant speed on the circular curve was considered admissible. Furthermore, different average distances of deceleration and acceleration were found. That highlights the correctness of assuming different values of deceleration and acceleration rate.

The most important limitation of the models based on speed spot-data is that data are not collected at the beginning and the ending deceleration/acceleration points. It derives into acceleration and deceleration profiles that not represent the actual driver behavior. Besides, deceleration and acceleration length cannot be determined, so the actual acceleration and deceleration rates cannot be accurately obtained.

To avoid these deficiencies in data collection, there are other methods based on continuous speed tracking, such as instrumented test vehicles or different methods based on digital video recording and processing. Each one are designed to different situations, i.e. digital video processing is only suitable for local studies in a reduced road segment.

Yang and Hassan (11) and $\mathrm{Hu}$ and Donnell (12) studied drivers' behavior from speed data collected using instrumental vehicle. However, the results and the possible developed speed models may be conditioned by the vehicle equipment and the number of observations. Moreover, the sample is not representative enough of the actual driver behavior because volunteers research participants knowing the research objectives.

That's why the data used in this study were from a field experiment based on GPS tracking devices. The main advantage of this method is the huge amount of continuous speed data collected without significant influence over the drivers. This new methodology lets the researchers, for the first time, to develop operating speed models on curves and tangents and to evaluate the speed differential on tangent-curve transitions, developing also deceleration and acceleration models. 


\section{OBJECTIVES}

The objective of this study is to develop operating speed prediction models for curves and tangents for two-lane rural roads, including geometric characteristics as explanatory variables. Furthermore, the research comprises the evaluation of speed variations from tangent to curve sections. To evaluate this phenomenon, several variables, such as the $85^{\text {th }}$ percentile speed differential $\left(\Delta_{85} \mathrm{~V}\right)$, the differential of $85^{\text {th }}$ percentile speed $\left(\Delta \mathrm{V}_{85}\right)$, deceleration length and deceleration length inside the curve, have been studied and a deceleration rate model has also been developed.

The research is not based on speed spot-data, but on continuous data. Consequently, models and results obtained, based on the same sample size, may be more accurate than the previous ones.

Therefore, the aim of this paper is not only to explain the obtained results and models but rather a new methodology to collect and process continuous speed data.

\section{FIELD STUDY}

In order to obtain the necessary speed continuous data for the analysis, a new methodology has been developed. The first step consists in data collection using GPS devices. The second step is the data reduction, including filtering and processing data. The results of this step are the horizontal alignment restitution, plotted as curvature diagram, and the individual operating speed continuous profiles.

\section{Data collection}

The speed data were collected between February 2008 and July 2008 during morning period between 8:30 a.m. and 2:00 p.m., in a working day and under dry weather conditions.

Speed data were collected using a pocket-sized GPS device. The available passive GPS trackers have an internal computer that accurately determines the GPS location of the device and records detailed travel data every second, such as time and position. Data stored on the GPS device can be accessed by inserting the unit directly into a personal computer via USB port for further processing.

Four two-lane rural road segments, with no main intersections and with a high lateral clearance, were selected for data collection phase. All the roads selected are characterized by low traffic volume to reduce the potential for restricted vehicle flow but enough to guarantee a significant sample size, and by low heavy traffic volume. The longitudinal grade never exceeded $\pm 4.0 \%$ because the analysis was limited to the horizontal alignment. The general road segments characteristics and the number of observations for each one are summarized in table 1.

At each end of road segment, drivers' cooperation was asked in order to install the GPS device on their vehicles thanks to its strong magnetic mounts. The drivers were encouraged to drive as they usually do, telling them that data were going to be used for a University research, not for enforcement. The device was finally collected at the other road control located at the segment end.

A survey was conducted both at the beginning and at the end of the road segment. While at the beginning control road the questions were about age, gender, number of occupants, driving experience, knowledge of the particular road segments, travel purpose, vehicle type; at the end control road the drivers were asked about posted speed, desirable speed and whether they had been influenced or not in their speed by another vehicle. The first survey lasted for two minutes. Thus, road segments were chosen with a maximum length of $9 \mathrm{~km}$ to avoid that a vehicle was caught up by the next one in order to guarantee free-flow conditions. Operating speed must be measured for the vehicles in the traffic stream under free-flow conditions to avoid the effect of traffic flow on vehicle speed. In this study, it is considered that the data representing the free-flow conditions are those of isolated vehicles with a minimum headway of at least 5 seconds.

This data collection method allows to obtain continuous speed data along a road segment and a great number of drivers' individual data. Nevertheless, this method might affect drivers' behavior. To guarantee the results' quality, it is necessary to check whether the operating speed during the data collection is significantly different from the normal operating speed. 
Along three of the data collection road segments, two camcorders were installed away from the drivers' sight in order to record the vehicles passing across a tangent section and across a curve section on each site. This process was carried out at the data collection day (with GPS) and a week before (without GPS). After the digital video processing, the statistical equality of both populations, with GPS and without GPS, was confirmed thanks to LSD (Least Significant Differences) intervals. The corresponding LSD intervals are presented in figure 1. As the intervals overlap, the population means are no significantly different from each other at the $95 \%$ confidence level.

\section{Data reduction}

Data collected by the GPS devices are presented in a latitude-longitude-altitude-compass bearing-timedate format, providing it in a 1-second interval. The data-processing program, developed for the present research, uses UTM (Universal Transverse Mercator) coordinates, so it was necessary to develop a program module to make the coordinate conversion. Occasionally, GPS devices stored anomalous data, so it was necessary to detect and take them out by another program module.

Once the GPS data conversion and debugging were carried out, the processing could begin. The first step was to define the starting and ending point for each one of the road segments. From these points, the program combines all individual paths in order to obtain the average operating trajectory.

From this average path it is possible to determine its curvature diagram and use it to obtain the horizontal alignment. The figure 2 shows an example of curvature diagram.

Considering each one of the drivers' trajectories it is possible to determine their individual operating speeds along the entire road segment. Thus, different speed percentiles can be obtained by considering all the individual speeds.

In order to guarantee free-flow conditions, a study by using speed percentiles was carried out, removing all the trajectories which presented abnormal speed behaviors. This study consisted in plotting several percentile speed profiles and comparing each individual trajectory with them. An example of an abnormal individual speed profile is the one that shows a located speed reduction much higher than the speed reduction of the percentile speed profiles at that point.

By means of these diagrams, it is not difficult to identify maximum and minimum speeds, deceleration points and speed variations. Therefore, this methodology might become a powerful tool for investigation.

\section{MODELS DEVELOPMENT}

Considering the curvature diagram developed by the data reduction process, the representative variables of the horizontal alignment of the road segment were obtained. The most important variables are the curve radii, curve length, deflection angle and tangent length. The curve radii varies from $80 \mathrm{~m}$ to $930 \mathrm{~m}$, the curve length from $55 \mathrm{~m}$ to $205 \mathrm{~m}$, the deflection angle from $4.5^{\circ}$ to $38.7^{\circ}$ and the tangent length from $25 \mathrm{~m}$ to $2590 \mathrm{~m}$.

A sight index was defined as the percentage of curve length that can be seen from the beginning point of the curve. Thus, when the index value is 1 , the whole curve length can be seen from the beginning of the curve. The sight distance index varies from 0.1 to 1.6.

Finally, considering that the curvature change rate has already been extensively investigated and that the results of the statistical analysis showed a good correlation between this index and the operating speed, the curvature change rate (CCR) of a single curve, including circular curve and transition curves, was selected as a variable.

Where,

$$
C C R=\frac{\left|\gamma_{i}\right|}{L_{C i}}
$$

$C C R=$ curvature change rate $($ degree $/ \mathrm{km})$. In this study, CCR varied from 55.62 degree $/ \mathrm{km}$ to 485.37 degree $/ \mathrm{km}$.

$\gamma_{\mathrm{i}}=$ deflection angle of the curve (degrees)

$L_{C i}=$ curve length $(\mathrm{km})$ 
The relation between these variables and operating speed, deceleration rate and speed variation was studied in order to develop the different models.

\section{Operating speed model on curves}

In order to develop the operating speed models on curves, the minimum speed at each curve was used, taken from the $85^{\text {th }}$ percentile speed profiles obtained in data reduction.

A preliminary ANOVA analysis among the horizontal alignment variables (curvature change rate, radius, etc) and operating speed on curves was performed. From this analysis, it was found that previous tangent length and sight distance index had a p-value of 0.3050 and 0.1428 , respectively. Therefore, these variables have not a statistically significant relationship with operating speed at the $90 \%$ confidence level. The variables with lowest $\mathrm{p}$-value were radius, curve length and CCR, so those were used in different regression analysis. However, the model obtained with curve length does not explain accurately the operating speed behavior, so the radius and the CCR were the explanatory variables used in the final models.

The regression analysis yield the model showed in figure 3 with radius as explanatory variable, having a $\mathrm{R}^{2}$ equal to 0.76 . This model is valid for a range of radii between $80 \mathrm{~m}$ and $930 \mathrm{~m}$.

The model presents a high slope for small radius, decreasing as radius gets larger. It indicates that for large radii curves, the radius is not as significant in the speed choice as for sharp curves. In fact, for radius higher than $500 \mathrm{~m}$ the model is consistently overpredicting the observed speeds.

Considering the trend of data, an operating speed model for curves with radius lower than $400 \mathrm{~m}$ will represent drivers' behavior more accurately for this range. Thus, another model was developed to estimate the operating speed on curves with those radii. This model, depending on $1 / \mathrm{R}$ (figure 3), presents a $\mathrm{R}^{2}$ equal to 0.84 . Its coefficient of determination is higher than the obtained for the global model, but lower than the one obtained for the linear model. However, this model fits better the phenomenon.

On the other hand, based on the CCR as explanatory variable, another global model was obtained by the regression analysis, with a $\mathrm{R}^{2}$ equal to 0.79 . This model is also presented at figure 3 with the data used on its development.

\section{Operating speed model on tangents}

On short tangents speed cannot be fully developed because of the influence of the adjacent curves. Therefore, for the model development the tangents used were those with enough length to be independent. These tangents were identified in the speed profiles as the tangents that presented a segment at which constant speed was attained. In all cases, the length of independent tangent was higher than $90 \mathrm{~m}$.

This model was developed by using, as tangent speed data, the mean of the $85^{\text {th }}$ percentile speeds presented in the tangent segment where the speed was approximately constant. These data might not coincide with the speed data corresponding to the middle point of the tangents.

Before stating the model expression, the drivers' behavior along a tangent must be taken into account. Along a tangent the speed increases with the length until the desired speed is reached. Therefore, the model must be asymptotical. Besides, the speed increment is smaller for large previous curve radius. Consequently, the slope of the model curve must be variable, depending on previous curve radius. These considerations led to the model presented in figure 4 with a $\mathrm{R}^{2}$ equal to 0.52 .

The proposed model includes: model.

- $\mathrm{V}_{85}(\mathrm{~km} / \mathrm{h})$ is defined as the estimated $85^{\text {th }}$ percentile speed on tangents obtained from the

- $\quad \lambda$ has been calibrated minimizing the MSE.

- $\mathrm{V}_{85} \mathrm{c}(\mathrm{km} / \mathrm{h})$ is defined as $85^{\text {th }}$ percentile speed on previous curves obtained from the proposed speed model for curves.

- $\mathrm{V}_{\text {des }}(\mathrm{km} / \mathrm{h})$ is the desired speed. The desired speed is defined as the speed at which drivers choose to travel under free-flow conditions when they are not constrained by alignment features. In this 
research its value has been assumed equal to $110 \mathrm{~km} / \mathrm{h}$ corresponding to the speed data registered in the longest tangents.

- $\quad \mathrm{L}(\mathrm{m})$ is the tangent length.

\section{Tangent-curve speed variations}

The current approach to evaluate design consistency is based on calculating the operating speed of the drivers on both the curved and the tangent sections and, then, subtracting these two values and naming it as the speed differential value. However, according to Hirsh (13) and McFadden and Elefteriadou (14), speed distributions at the curved and tangent sections are not the same, and thus the simple subtraction of the operating speed values should not be performed. Also, even if the speed distributions are the same, the $85^{\text {th }}$ percentile driver does not need to be the same in the two locations. Moreover, most previous research based these calculations on data collected at two sections, without verification whether these data correspond to the speed at the beginning and end points of deceleration.

Thanks to the continuous speed profile obtained by the methodology presented in this paper, the beginning and end points of deceleration and the associated speeds, both the $85^{\text {th }}$ percentile and the individual ones have been determined. Thus, in present research speed differential $\left(\Delta \mathrm{V}_{85}\right)$ was calculated for each individual vehicle using their individual speed at beginning and end points of its deceleration. Besides, the statistic $\Delta_{85} \mathrm{~V}$ ( $85^{\text {th }}$ percentile speed differential) was calculated. It is defined as the differential speed not exceeded by $85 \%$ of the drivers traveling under free-flow conditions.

Figure 5 shows the representation of $\Delta_{85} \mathrm{~V}$ in relationship with $\Delta \mathrm{V}_{85}$.

Based on the observations of this study, it can be concluded that the simple subtraction of operating speed underestimates the actual values of speed differential. This conclusion is similar to the conclusions carried out by McFadden and Elefteriadou (14) and Misaghi and Hassan (8).

\section{Deceleration model}

Deceleration model tries to complete the operating speed profile model, reflecting as accurate as possible the drivers' behavior in a tangent-to-curve transition. This problem is generally solved by using deceleration rates, obtained by the equation (2).

$$
d=\frac{V_{85(i)}^{2}-V_{85(i+1)}^{2}}{2 D}
$$

Where,

$V_{85(i)}$ and $V_{85(i+1)}=$ operating speeds in the locations (i) and (i+1)

$D=$ the distance between the locations (i) and (i+1)

However, according to Bella (10) the deceleration rate calculated on the basis of the individual driver behavior is significantly higher than the one obtained from the operating speed profiles. Consequently, the methodology for the determination of the deceleration rate on the basis of the operating speeds leads to an underestimation of the deceleration and acceleration rates effectively experienced by the drivers.

Taking into account these considerations, the value of the deceleration rate in the tangent-to-curve transition was calculated based on individual driver speed profile by the equation (3).

$$
d_{i}=\frac{V_{T(i)}^{2}-V_{C(i)}^{2}}{2 D}
$$

Where,

$V_{T(i)}=$ individual speed at the beginning point of deceleration in the tangent

$V_{C(i)}=$ individual speed at the end point of deceleration in the curve

$D=$ the distance between the beginning and the end point of deceleration

Once the decelerations of the individual drivers have been obtained, the value of the $85^{\text {th }}$ percentile $\left(\mathrm{d}_{85}\right)$ was determined for every configuration and a correlation analysis was performed in order 
to determine which independent variables are correlated with this rate. An ANOVA analysis revealed that a positive and strong correlation exists between $d_{85}$ and inverse of radius ( $p$-value $=0.00$ ) and the CCR of the single curve ( $\mathrm{p}$-value $=0.00)$.

Based on the values of $d_{85}$ calculated from the individual speed profiles and on the results of the correlation analysis, models that predict the expected deceleration were developed. The regression analysis yield the model shown in figure 6 with radius as explanatory variable, having a $\mathrm{R}^{2}$ equal to 0.70 .

Since the model estimates the deceleration rate when a vehicle enters a horizontal curve that increases as radius decreases, the models appears to be congruent.

The curve radius was not the only significant variable, but a strong correlation between the deceleration rate and the CCR was also confirmed. Therefore, another alternative model to predict the deceleration from CCR data has been developed. This model is shown in figure 6 .

In the study of deceleration phenomenon it is not only important to consider the deceleration rates, but also the deceleration length. Several research assumed that the speed remains constant throughout a curve and that the deceleration occurs entirely on the approach tangent.

Thanks to the continuous observed speed profiles these assumptions have been invalidated. The study of collected data found out that at least the $7 \%$ of the deceleration transition length occurs on the curve. The average deceleration transition length that occurs on the curve is $47.34 \%$. There are values even higher than $89 \%$.

Moreover, the average percentage of curve length affected by deceleration is $45 \%$, and in the $58 \%$ of sites deceleration finishes before curve's midpoint.

\section{MODELS COMPARISON}

The developed models have been compared to others existing in the literature. All models were applied to the geometric elements obtained from the curvature diagram developed for different road segments than those ones used for calibrating the models, estimating the operating speed on curves and tangents and the deceleration rates. After that, the minimum square error (MSE) and root minimum square error (RMSE) have been calculated for each model. In table 2 all the results are summarized.

Concerning to operating speed on curves, the three models developed in this research fit better to the drivers' behavior in the studied roads, presenting less MSE and RMSE than the others.

Tangent models present a lower MSE difference. However, the current operating speed model for tangents includes in its equation the operating speed model for curves. This issue is important in order to develop continuous speed profiles.

Previous deceleration models were calibrated by using speed spot-data. Therefore, rates obtained with those models do not consider the correct speed variation length. Besides, they use a unique length value to calculate decelerations, dealing to non-accurate results. Moreover, most of them calculate the deceleration rate considering the $\mathrm{V}_{85}$ variations, instead of the individual speed differences.

These limitations are avoided by considering the individual continuous speed profiles. It implies that the results obtained with this new methodology lead to a more accurate estimations. In fact, the MSE and MRSE obtained with the proposed models are considerably lower.

\section{CONCLUSIONS}

This paper presents a new data collection methodology that allows developing continuous speed profiles. By using these data, it is possible to study accurately drivers' behavior and to develop accurate operating speed and deceleration models.

Three operating speed models for curves have been calibrated. Several variables have been studied for this purpose, such as: radius; CCR; curve length; and previous tangent length. After a preliminary ANOVA evaluation, radius and CCR have been chosen as explanatory variables in two alternative models. Another lineal model has been proposed for curve with $\mathrm{R}<400 \mathrm{~m}$.

In order to obtain the operating speed model expression for curves, a regression analysis has been carried out. However, in the case of tangents, considering drivers' behavior is necessary to establish 
previously a model expression. As a result, the proposed model is asymptotical and shows a decreasing speed increment as curve radius increases.

The speed variation on tangent-curve transitions was also studied. To evaluate this phenomenon several variables, such as $\Delta_{85} \mathrm{~V}, \Delta \mathrm{V}_{85}$, deceleration length and deceleration length inside the curve, have been studied and two deceleration rate models have been developed.

From the study of the $\Delta_{85} \mathrm{~V}$ and $\Delta \mathrm{V} 85$, it can be concluded that the simple subtraction of operating speed underestimates the actual values of speed differential. Its evaluation can be done accurately thanks to the observed individual continuous speed profiles.

From these profiles, the deceleration lengths occurring in the curve have also been studied, refusing the assumption that the deceleration process occurs entirely in the approach tangent.

Finally, two deceleration models have been presented. While the first one depends on the inverse of radius, the second have the CCR of the individual curve as explanatory variable. These models have been calibrated by using the $85^{\text {th }}$ percentile of deceleration, calculated based on individual driver speed profile.

These models have been compared with the models developed by other authors, resulting in a better fit to actual operating speed for the geometric characteristics of the examined roads.

All these results can be achieved by means of the individual continuous speed profiles obtained from data collection. Applying them, it is not difficult to identify maximum and minimum speeds, deceleration points and speed variations. Therefore, this methodology becomes as a promise and powerful tool for driver behavior investigation. 


\section{ACKNOWLEDGEMENTS}

Authors would like to thank Center for Studies and Experimentation of Public Works (CEDEX) of the Spanish Ministry of Public Works that partially subsidizes the research. Also thank to the Infrastructure and Transportation Department, General Directorate of Public Works, Valencian Government, Spain, Valencian Provincial Council and to the Ministry of the Interior, General Directorate of Traffic, Spain, for their cooperation in field data gathering. 


\section{REFERENCES}

1. Lamm, R., Psarianos, B. and Mailaender, T. Highway design and Traffic Safety Engineering Handbook. McGraw-Hill, New York, 1999.

2. Ottesen, J.L. and Krammes, R.A. Speed profile model for a design consistency evaluation procedure in the United States. In Transportation Research Record: Journal of the Transportation Research Board, No. 1701, Transportation Research Board of the National Academies, Washington, D.C., 2000, pp. 76-85.

3. Fitzpatrick, K. and Collins, J. Speed-profile model for two-lane rural highways. In Transportation Research Record: Journal of the Transportation Research Board, No. 1737, Transportation Research Board of the National Academies, Washington, D.C., 2000, pp. 42-49.

4. Fitzpatrick, K., Elefteriadou, L., Harwood, D. W., Collins, J. M., McFadden, J., Anderson, I., Krammes, R. A., Irizarry, N., Parma, K. D., Bauer, K. M. and Passetti. K. Speed Prediction for TwoLane Rural Highways. Draft Report FHWA-RD-99-171. FHWA, U.S. Department of Transportation, 1999.

5. Polus, A., Fitzpatrick, K. and Fambro, D. Predicting operating speeds on tangent sections of two-lane rural highways. In Transportation Research Record: Journal of the Transportation Research Board, No. 1737, Transportation Research Board of the National Academies, Washington D.C., 2000, pp. 50-57.

6. Collins, K.M. and Krammes, R.A. Preliminary validation of a speed-profile model for design consistency evaluation. In Transportation Research Record: Journal of the Transportation Research Board, No. 1523, Transportation Research Board of the National Academies, Washington D.C., 1996, pp. $11-21$.

7. Gibreel, G. M, Easa, S. M. and El-Dimeery, I.A. Prediction of operating speed on three-dimensional highway alignments. Journal of Transportation Engineering, ASCE, Vol. 127, 2001, pp. 21-30.

8. Misaghi, P. y Hassan, Y. Modeling Operating Speed and Speed Differential on Two-Lane Rural Roads. Journal of Transportation Engineering, ASCE, Vol. 131, No. 6, 2005, pp. 408-417.

9. Figueroa, A.M. and Tarko, A.P. Speed changes in the vicinity of horizontal curves on two-lane rural roads. Journal of Transportation Engineering, ASCE, Vol. 133, No. 4, 2007, pp. 215-222.

10. Bella, F. Assumptions of operating speed-profile models on deceleration and acceleration rates: verification in the driving simulator. $87^{\text {th }}$ Annual Meeting Transportation Research Board, Washington D.C., 2008.

11. Yang, L. and Hassan, Y. Driver Speed and Acceleration Behavior on Canadian Roads. $87^{\text {th }}$ Annual Meeting of the Transportation Research Board, Washington, D.C., 2008.

12. Hu, W. and Donnel, E.T. Models of Acceleration and Deceleration Rates on a Complex Two-Lane Rural Highway: Results from a Nighttime Driving Experiment. 87 $7^{\text {th }}$ Annual Meeting of the Transportation Research Board, Washington, D.C., 2008.

13. Hirsh, M. Probabilistic approach to consistency of highway alignment. Journal of Transportation Engineering, ASCE, Vol. 113, No. 3, 1987, pp. 268-276.

14. McFadden, J. and Elefteriadou, L. Evaluating horizontal alignment design consistency of two-lane rural highways: Development of new procedure. In Transportation Research Record: Journal of the Transportation Research Board, No. 1737, Transportation Research Board of the National Academies, Washington, D.C., 2000, pp. 9-17. 


\section{LIST OF TABLES AND FIGURES}

TABLE 1 Summary of Road Segments Characteristics TABLE 2 Models Comparison

FIGURE 1 LSD Intervals for Methodology Validation.

FIGURE 2 Curvature Diagram.

FIGURE 3 Operating speed model for curves.

FIGURE 4 Operating speed model for tangents.

FIGURE $5 \Delta_{85} \mathrm{~V}$ vs $\Delta \mathrm{V}_{85}$.

FIGURE 6 Deceleration model. 
TABLE 1 Summary of Road Segments Characteristics

\begin{tabular}{|c|c|c|c|c|c|}
\hline & \multicolumn{4}{|c|}{ ROAD SEGMENT } \\
\hline & & CV-333 & $\mathrm{CV}-370$ & CV-401 & $\mathrm{CV}-376$ \\
\hline \multicolumn{2}{|c|}{ Road segment length } & $5.1 \mathrm{~km}$ & $8.3 \mathrm{~km}$ & $6 \mathrm{~km}$ & $6.7 \mathrm{~km}$ \\
\hline \multicolumn{2}{|c|}{ Number of curves } & 4 & 21 & 18 & 38 \\
\hline \multicolumn{2}{|c|}{ Number of tangents } & 5 & 21 & 16 & 11 \\
\hline \multicolumn{2}{|c|}{ Number of tangent-curve sections } & 4 & 8 & 10 & 6 \\
\hline \multicolumn{2}{|l|}{ Lane width } & $3.35 \mathrm{~m}$ & $3.13 \mathrm{~m}-3.33 \mathrm{~m}$ & $3.55 \mathrm{~m}-4.03 \mathrm{~m}$ & $3.25 \mathrm{~m}$ \\
\hline \multicolumn{2}{|l|}{ Shoulder width } & $1 \mathrm{~m}$ & $0 \mathrm{~m}-1 \mathrm{~m}$ & $0 \mathrm{~m}-0.4 \mathrm{~m}$ & $0 \mathrm{~m}-0.80 \mathrm{~m}$ \\
\hline \multirow{2}{*}{ Observations* } & Forward direction & 110 & 65 & 87 & 26 \\
\hline & Backward direction & 88 & 74 & 86 & 46 \\
\hline
\end{tabular}

*number of observations after removal of non-free-flow vehicles. 
TABLE 2 Models Comparison

\begin{tabular}{|c|c|c|c|}
\hline \multicolumn{4}{|c|}{ OPERATING SPEED MODELS ON CURVES } \\
\hline MODEL & EQUATION & MSE & RMSE \\
\hline Lamm et al (1999) & $V_{85}=95.594-1.597 \cdot D C$ & 341.01 & 18.47 \\
\hline $\begin{array}{c}\text { Fitzpatrick and } \\
\text { Collins }(2000) \\
\text { Grade }-4 \% \leq \mathrm{G}<0 \%\end{array}$ & $V_{85}=105.98-3709.90 / R$ & 73.20 & 8.56 \\
\hline $\begin{array}{c}\text { Fitzpatrick and } \\
\text { Collins }(2000) \\
\text { Grade } 0 \% \leq \mathrm{G}<4 \%\end{array}$ & $V_{85}=104.82-3574.51 / R$ & 89.98 & 9.49 \\
\hline $\begin{array}{l}\text { Ottesen and Krammes } \\
(2000)\end{array}$ & $V_{85}=103.66-1.95 \cdot D C$ & 73.36 & 8.56 \\
\hline $\begin{array}{l}\text { Ottesen and Krammes } \\
(2000)\end{array}$ & $V_{85}=102.44-1.57 \times D C-0.012 \times L_{C}-0.01 \times D C \times L_{C}$ & 57.87 & 7.60 \\
\hline Pérez et al (2010) & $V_{85}=97.4254-3310.94 / R$ & 30.45 & 5.52 \\
\hline Pérez et al (2010) & $V_{85}=1 /(0.00948323+0.0000136809 \cdot C C R)$ & 15.34 & 3.92 \\
\hline $\begin{array}{c}\text { Pérez et al (2010) } \\
\mathrm{R}<400 \mathrm{~m} \\
\end{array}$ & $V_{85}=102.048-3990.26 / R$ & 35.04 & 5.91 \\
\hline \multicolumn{4}{|c|}{ OPERATING SPEED MODELS ON TANGENTS } \\
\hline Polus et al (2000) G1 & $V_{85}=101.11-3420 / G M$ & 87.38 & 9.34 \\
\hline Polus et al (2000) G2 & $V_{85}=105-28.107 / e^{0.00108 \cdot G M}$ & 79.18 & 8.89 \\
\hline Polus et al (2000) G3 & $V_{85}=97.73-0.00067 \cdot G M$ & 98.08 & 9.90 \\
\hline Polus et al (2000) G4 & $V_{85}=105-22.953 / e^{0.00012 \cdot G M}$ & 84.32 & 9.18 \\
\hline Pérez el al (2010) & $V_{85}=V_{85 C}+\left(1-e^{-\lambda L}\right) \cdot\left(V_{\text {des }}-V_{85 c}\right)$ & 77.52 & 8.80 \\
\hline \multicolumn{4}{|c|}{ DECELERATION MODELS } \\
\hline $\begin{array}{l}\text { Fitzpatrick et al } \\
\text { (2000) }\end{array}$ & $d_{85}=0.6794-295.14 / R$ & 0.35 & 0.59 \\
\hline Pérez et al (2010) & $d_{85}=0.263571+67.7999 / R$ & 0.0084 & 0.092 \\
\hline Pérez et al (2010) & $d_{85}=0.242186+0.00150693 / C C R$ & 0.0084 & 0.091 \\
\hline
\end{tabular}

Where,

$D C=$ degree of curvature (degrees per $100 \mathrm{ft}$ of arc)

$L_{C}=$ curve length (m)

$G M=$ geometric measure (Polus et al., 2007) 


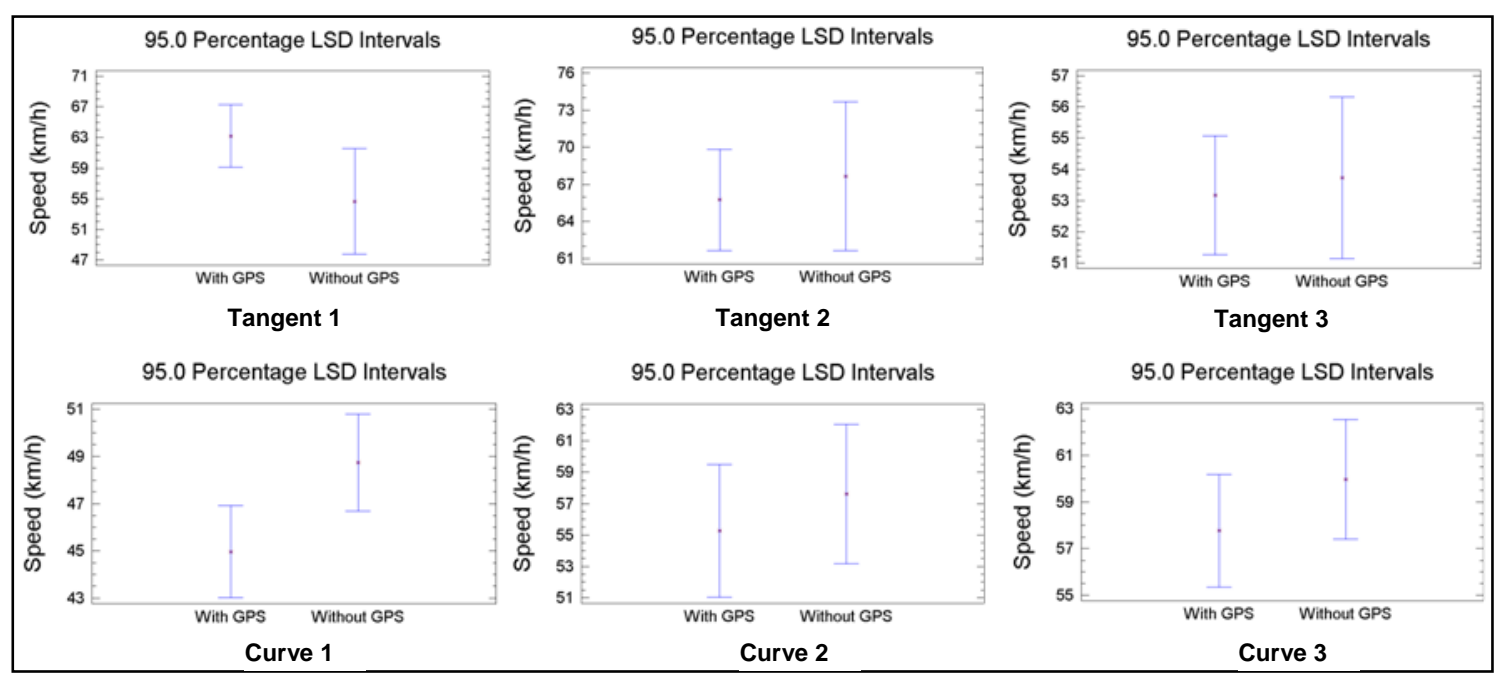

FIGURE 1 LSD Intervals for Methodology Validation. 


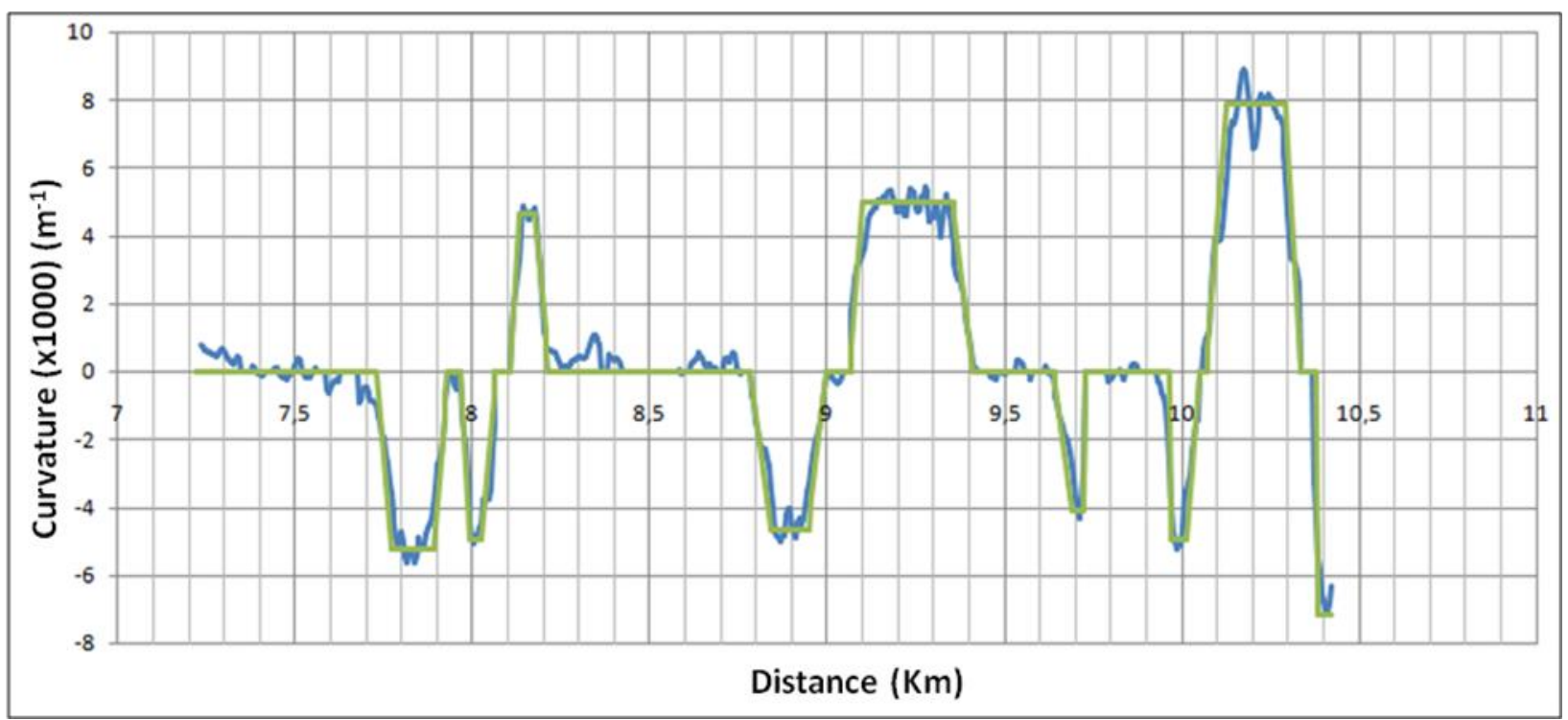

FIGURE 2 Curvature Diagram. 


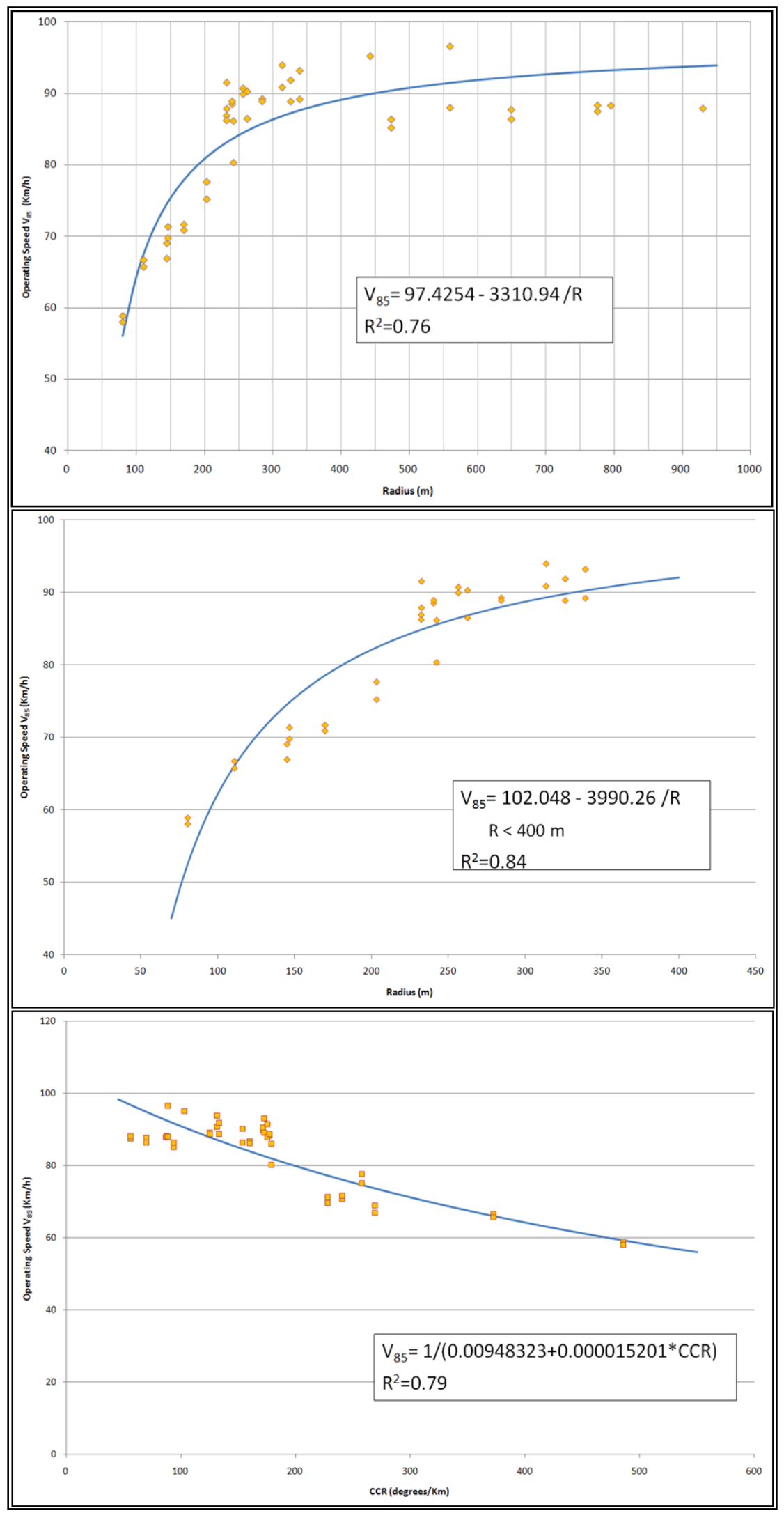

FIGURE 3 Operating speed model for curves. 


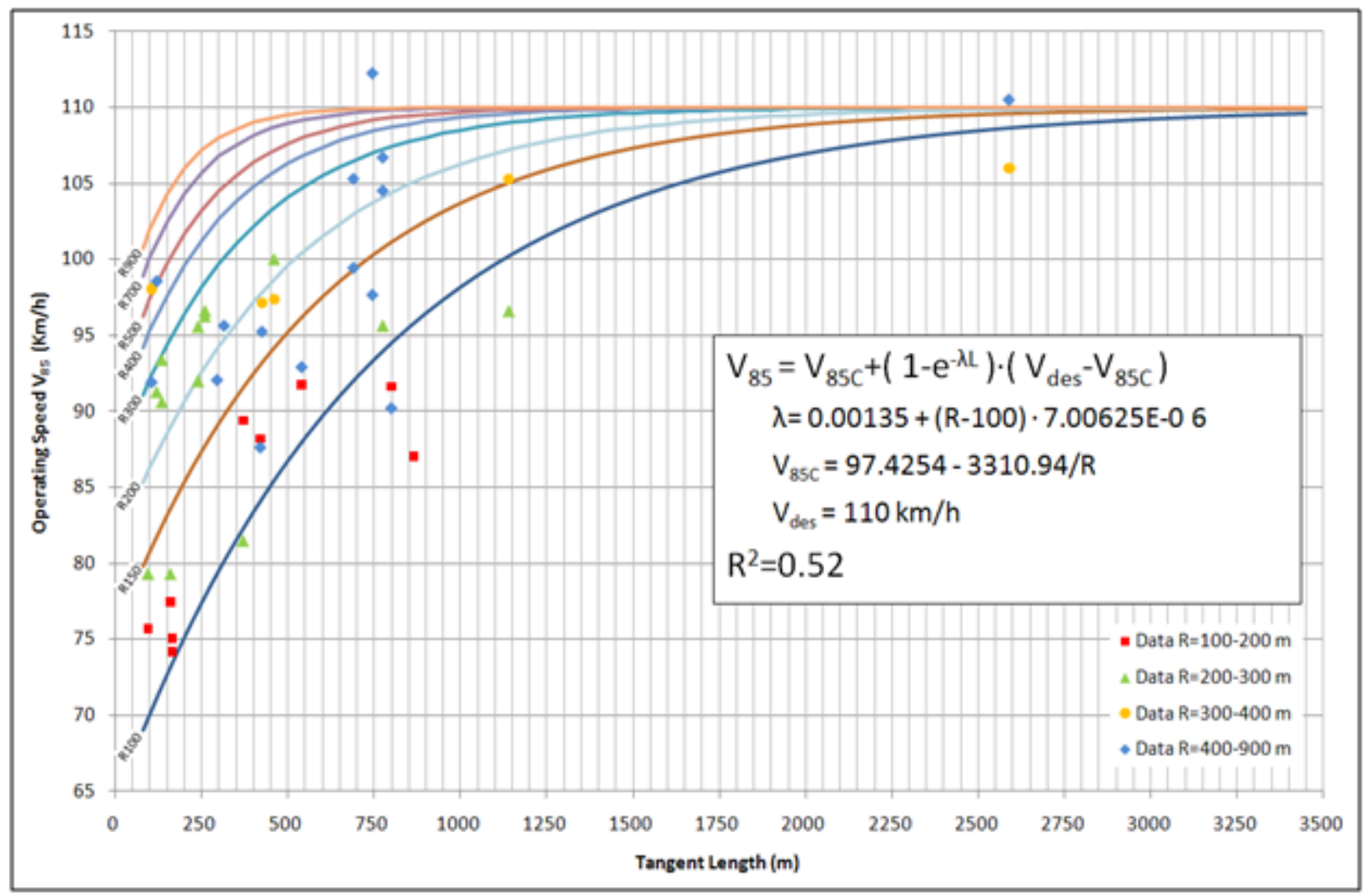

FIGURE 4 Operating speed model for tangents. 


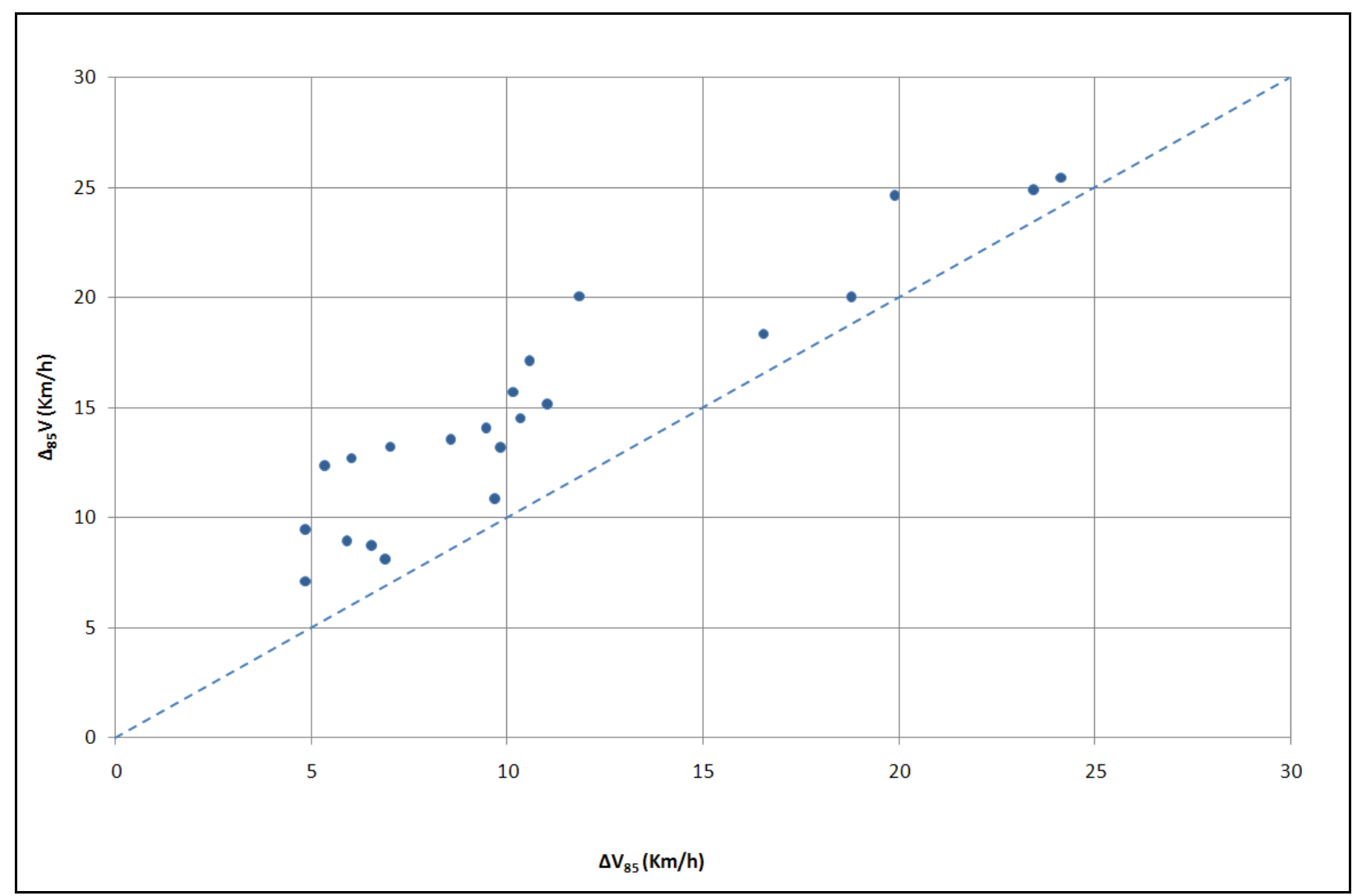

FIGURE $5 \Delta_{85} V$ vs $\Delta V_{85}$. 


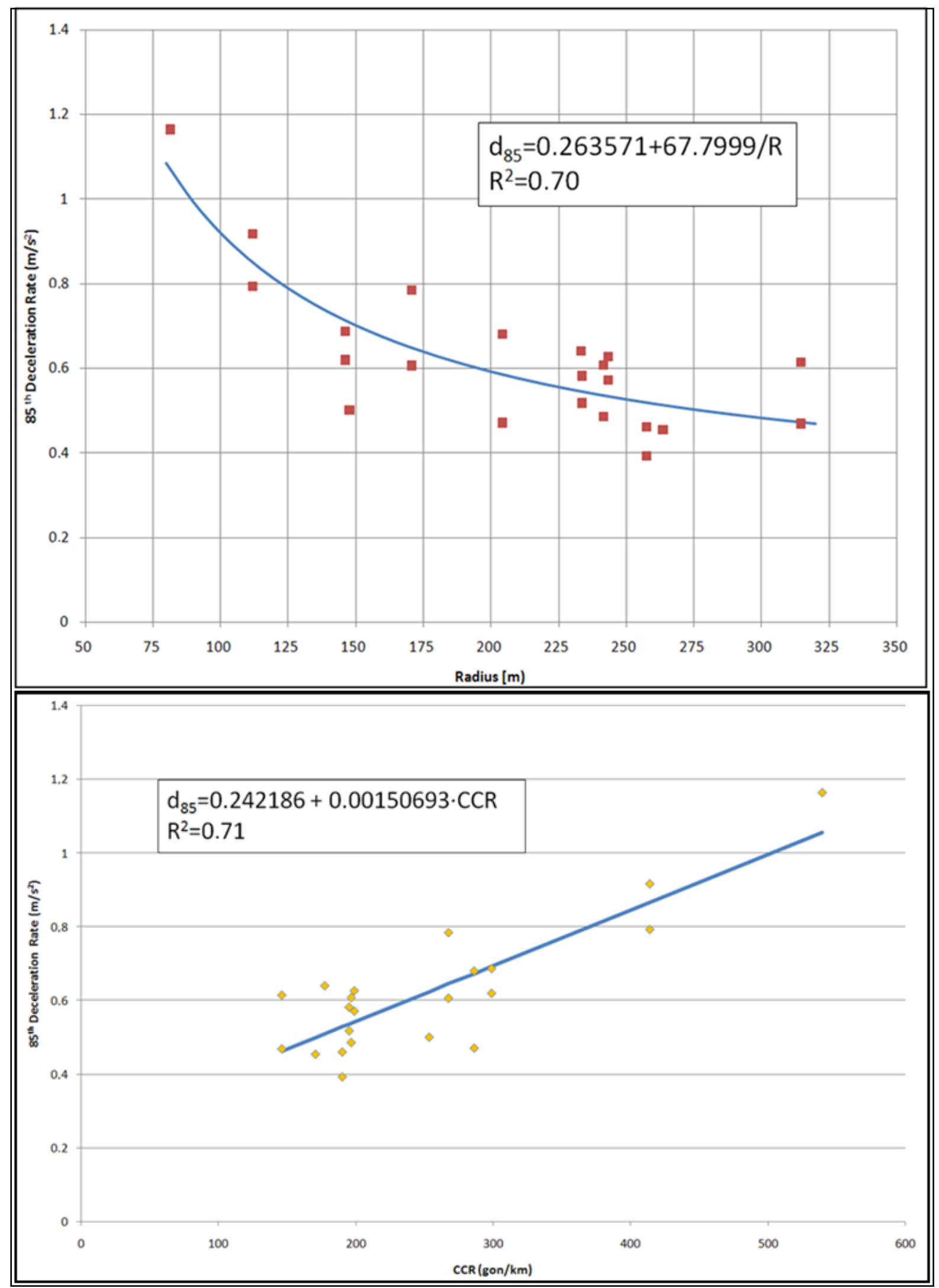

FIGURE 6 Deceleration model. 
PÉREZ, A.M., GARCÍA, A., CAMACHO, F.J. and D'ATTOMA, P. 